MEDIAÇÃO JUDICIAL NO BRASIL: BREVES NOTAS CONCEITUAIS À LUZ DE PRINCÍPIOS CONSTITUCIONAIS | JUDICIAL MEDIATION IN BRAZIL: BRIEF CONCEPTUAL NOTES WITH OF CONSTITUTIONAL PRINCIPLES

\title{
TÂNIA MARIA DOS SANTOS
}

RESUMO | A utilização da expressão "mediação judicial" pode ser considerada um indicador da problemática que, no presente trabalho, se propõe a investigar e construir pontes conceituais entre uma atividade, a mediação, que tende a ser mais prática com outra, e a judicial, que é mais técnica e teórica. A mediação é apresentada como um caminho que facilita, ou restabelece a capacidade de diálogo sobre situações conflituosas entre pessoas, grupos ou organizações. Para tanto, será distinguida a mediação judicial de outros meios alternativos, Resoluções Adequadas de Disputas (RAD), serão particularizados papéis de advogados, juízes e mediadores diante do avançado instrumento jurídico pátrio, e examinará alguns princípios. Ao fim da pesquisa, contempla-se que a mediação judicial, como fio condutor democrático, tem base em direitos fundamentais dos quais foram desprendidos os do acesso à justiça e o da solidariedade, pois o escopo desses princípios é levar o cidadão a sério e fortalecer a civilidade na sociedade.

PALAVRAS-CHAVE | Mediação. Princípios. Democracia. Acesso à Justiça. Solidariedade.
ABSTRACT | The use of the term "judicial mediation" can be considered an indicator of the problem, which in the present work proposes to investigate and build conceptual bridges between an activity, mediation, which tends to be more practical with another, judicial, which is more Technical and theoretical. Mediation is presented as a path that facilitates, or restores, the ability to dialogue about conflicting situations among individuals, groups, or organizations. To this end, judicial mediation will be distinguished from other alternative or suitable means of pacification, particularizing the roles of lawyers, judges and mediators in the new and advanced legal instrument of the country, and will examine some principles of judicial mediation. At the end of the research, it is contemplated that judicial mediation, with democratic guidelines, is based on fundamental rights, from which access to justice and solidarity have been derived; Therefore, the scope of these principles is to take the citizen seriously and to strengthen civility in society.

KEYWORDS | Mediation. Principles. Democracy. Access to Justice. Solidarity. 


\section{INTRODUÇÃO}

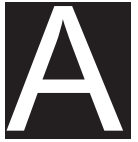

sociedade organizada e pluralista preceitua e almeja mecanismos eficazes para a expansão da paz social e o livre acesso à justiça. E o estado constitucional democrático é o campo ideal e necessário para uma tarefa difícil.

A alta eficiência dos meios de pacificação de conflitos, por serem de composição autônoma, tornou-se um importante meio contemporâneo de pacificação social pelo qual se busca uma "solução adequada" em vez de uma "solução adjudicada" e imposta.

No novo cenário legislativo nacional ${ }^{1}$, trazido em especial pelas Leis 13.105/2015 (novo CPC) e 13.140/2015 (Lei de Mediação), a solução dos conflitos pela jurisdição passou a ser tratada em caráter de excepcionalidade, isto é, nas situações em que as formas consensuais forem verdadeiramente incompatíveis, como direitos não disponíveis ${ }^{2}$, ou indisponíveis que admitam transação, quando um ou mais envolvidos expressam a vontade de não participar. Os institutos da mediação, conciliação e arbitragem foram contemplados no novo código de processo civil como Métodos Adequados de Resolução de Conflitos (MASC), que também foram reconhecidos mundialmente como Alternative Dispute Resolution (ADR), ou meios extrajudiciais de resolução de conflitos (MESCs) com o objetivo de evitar a judicialização massificada.

Desses preceitos, cabe elucidar dois pontos acerca da temática quando assistida de maneira expansiva ou ampla.

\footnotetext{
1 É de uma envergadura considerável esse novo cenário, levando-se em conta que nos EUA a mediação goza de grande prestígio e é disseminada em mais duas mil leis e regulamentações estaduais. Porém, é reclamada a ausência de uma legislação nacional de caráter unificador como a do Brasil neste sentido ressaltado no Centro de Mediadores de Brasília/DF na capacitação internacional em mediação e arbitragem e mediação Curso ministrado pelo Dr. Marcelo Markus Teixeira Módulo 1, 1.4, p. 2, em 2016.

2 Art. $3^{\circ}$ da Lei de Mediação: "Pode ser objeto de mediação o conflito que verse sobre direitos disponíveis ou sobre direitos indisponíveis que admitam transação. $\S 1^{\circ} \mathrm{A}$ mediação pode versar sobre todo o conflito ou parte dele. $\S 2^{\circ} \mathrm{O}$ consenso das partes envolvendo direitos indisponíveis, mas transigíveis, deve ser homologado em juízo, exigida a oitiva do Ministério Público".
} 
Primeiro, que não há hierarquia entre os meios de resolução de conflitos porque, para cada espécie, ou caso concreto de conflito, há um meio correspondente e mais adequado para a solução. Nesse sentido, pode-se inferir que o processo judicial é mais eficaz para decidir questões que abarquem direitos indisponíveis, ou quando não houver equilíbrio entre as partes; a arbitragem é mais eficaz em situações em que há particularidades técnicas; a conciliação ${ }^{3}$ é mais adequada para dirimir conflitos em relações descontinuadas e a mediação em relações que tendem a se prolongar no tempo. Retomaremos sobre outros tipos de resolução adiante.

Segundo, é indicado construir pontes entre a ciência do direito ${ }^{4} \mathrm{e}$ a mediação, em que pese serem mundos diferentes. A linguagem tem maior efeito e abrangência quando convence os que estão no mesmo mundo, ou aqueles que buscam estar no lugar ou no mundo do outro. E nessa façanha de enorme envergadura discursiva linguística, que aqui não é o objeto, torna-se coerente partir da ideia de que ambos não trabalham com discursos ${ }^{5}$ de realidades dadas. A ciência do direito tem por objeto a correção de raciocínios ${ }^{6}$ e defender uma realidade dada seria, no mínimo, ingênuo, porque abriria as portas para um proveito de

\footnotetext{
3 A Resolução $n^{\circ} 118 / 2014$, do CNMP, distingue a conciliação da mediação. Em seus arts. $9^{\circ} \mathrm{e}$ 10, a mediação é indicada para solucionar controvérsias ou conflitos nos quais seja necessária a atuação integrada de ambas as partes divergentes com o objetivo de se pacificarem. Indicase, ainda, que haja confidencialidade quando necessário e recomenda-se que as mediações comunitárias e escolares sejam informais (BRASIL. Conselho Nacional do Ministério Público. Resolução n. 118/2014. Disponível em: <www.cnmp.mp.br>. Acesso em: 23 jan. 2017).

4 Destacando que as atividades da ciência do direito, no sentido mais estrito e próprio, ocorrem em pelo menos três situações, que são: na descrição do direito vigente, na análise sistemática e conceitual e na elaboração de propostas para solução de casos jurídico-problemáticos. Neste sentido, HOLLERBACH, A. Ciência do direito. Tradução Eduardo Schenato Piñeiro. In: HECK, L. A. (org.). Direito natural, direito positivo, direito discursivo. Porto Alegre: Livraria do Advogado, 2010, p. $13-24$.

5 O discurso transforma-se, de fato, em mera conversa, quando as palavras nada revelam senão apenas um meio para alcançar um fim. Em BURKARD, F.-P.; PRECHET, P. (orgs.). Metzler Lexukon Philosophie. 3. Auflage. Stuttgart: Verlag J. B. Metzler, 2008, S. 106. O conceito geral de discurso é a designação de um diálogo realizado à base de argumentos. falar; é ser reflexivo; é levar o outro lado a sério.
} 
vocábulos ambíguos e fórmulas vazias ${ }^{7}$, enquanto a mediação judicial tem por objeto, em sentido amplo, corrigir distorções de entendimento, ou mal-entendidos, entre os mediados sem priorizar as bases fatuais jurídicas ou processuais.

Interessante alertar que tanto o direito quanto a mediação podem cair na mesma armadilha discursiva da superidealização. Levando, pois, em consideração o caráter dinâmico e aberto de ambas, qualquer parte ou mediando pode introduzir qualquer asserção de natureza e atuação ampla.

Assim, pode, de um lado, nos levar a situações em que a Lei Maior fosse encarada como ovo do mundo jurídico";; mas, por outro lado, a mediação como um "ovo de colombo" no qual tenderia a menosprezar caminhos percorridos em outros campos do conhecimento. Advertências são feitas deste da formação precípua do mediador judicial, que acordos ou soluções de controvérsia como meta principal não devem ser institucionalizados. Essa atitude pode ser avaliada como uma usurpação do significado e aplicação da Constituição Federal. Portanto, a mediação não é um meio de desafogar o Judiciário, ou panaceia, mas sim um caminho alternativo e adequado a uma sociedade contemporânea.

Diante do exposto, este trabalho está dividido em duas partes. Na primeira são examinados conceitos, bases legislativas, espécies, classificação sobre mediadores e métodos alternativos de solução de conflitos. Na segunda, o desafio será conduzir, através de fundamentos do Estado Constitucional Democrático, os princípios do acesso à Justiça e da solidariedade tão valiosos à mediação judicial.

7 Nesse sentido, LUDWIG, R. J. A norma de direito fundamental associada: direito, moral e razão em Robert Alexy. Porto Alegre: SAFE, 2014, p. 302-306.

8 ALEXY, 2011, p. 75-76, direciona que a jurisdição constitucional protege do risco da constitucionalização expansiva. 


\section{CONSIDERAÇÕES BASILARES SOBRE MEDIAÇÃO JUDICIAL}

\subsection{CONCEITO E ESPÉCIES}

Os conflitos ${ }^{9}$ envolvem grandes desafios na busca por estruturas técnicas necessárias, muitas vezes interdisciplinares, para aparelhar o jogo tenso e complexo no plano social-político-jurídico de um estado. Não há condições ideais no mundo real, é inviável incluir todos os argumentos ${ }^{10} \mathrm{e}$ inexistir engano.

A mediação de conflitos é obrigatória, em alguns países e em determinadas situações como em Estados dos EUA, da Argentina e da Itália ${ }^{11}$. Há de ser reconhecer, entretanto, que se acredita que essa solução não é adequada à realidade cultural brasileira, que exige

\footnotetext{
9 A noção de conflito é intuitiva porque são essenciais à vida humana; os conflitos nunca desaparecem completamente, mas pela natureza exigem uma espécie de gerência a qual provoca uma análise, por vezes, complexa. No momento, cumpre apenas destacar que a estrutura mínima do conflito é, universalmente, triangular, composta por duas pessoas e uma questão, e que nele atua-se sempre em três dimensões: a universal, a cultural e a individual, porque são compreendidos "como universalmente similares, culturalmente distintos e individualmente únicos", neste sentido ver AUGSBURGER, David W. Conflict mediation across cultures: pathways and patterns. Louisville KY: Westminster/John Knox Press, 1992, p. 17 apud BIANCHI, A.A.; JONATHAN, E.; MEURER, O.A. Teorias do conflito. In: ALMEIDA, T.; PELAJO, S.; JONATHAN, E. Mediação de conflitos. Salvador: Juspodivm, 2016, p. 72 . O livro de Ausburger é citado regularmente pela doutrina quando se busca analisar o conflito sob ângulo cultural, guiando sobre a transformação de conflitos (e não sobre a gestão ou resolução do conflito); destaca que a evitação de conflitos é uma orientação da sociedade chinesa, mas que pode levar à evasão do confronto e não a uma verdadeira resolução de conflitos. Daí as máximas: quanto mais orientado para a harmonia de um grupo, mais sensível ao conflito será o grupo; quanto mais comprometido o grupo a praticar o valor cultural da harmonia, mais intensamente o conflito será internalizado. Outro livro pertinente e muito interessante é do ENTELMAN, R.F. Teoría de conflitos - hacia un nuevo paradigma. Barcelona: Gedisa, 2009, no qual ele foge do lugar comum de confrontos entre grupos ou indivíduos como conflitos específicos e que não analizam o que Ihes é comum, ou que pode ser aplicado a outros conflitos e apresenta ferramentas conceituais com pretensão de universalizar resultados.

10 Etapas importantes na construção de um argumento são interpretação, pretensão de correção e a verificação pública, se for o caso, ou privada. Isto é, há de se ter o reconhecimento intersubjetivo de todos os envolvidos para concessões e assentimentos.

11 TARTUCE, F. Mediação nos conflitos civis. 2. ed. Rio de Janeiro: Forense, 2015.
} 
apenas uma comprovação da tentativa de uma solução consensual do conflito. No entanto, a designação de audiência de mediação é obrigatória no conflito coletivo de posse velha e nas ações de família ${ }^{12}$, que são procedimentos especiais.

A American Arbitration Association $(A A A)^{13}$ é um dos maiores responsáveis pela disseminação da cultura da mediação no mundo, tanto que incentiva a utilização da mediação anteriormente à utilização nos procedimentos arbitrais e aponta as vantagens fundadas no binômio tempo/dinheiro sobre a arbitragem. As regras de mediação, em geral, disponibilizam parâmetros claros, flexíveis e modernos na condução dos procedimentos e nada impede, entretanto, que regras de mediação possam ser aplicadas, ou mescladas, a outros tipos de resolução amigável de conflitos, conforme ver-se-á adiante.

A cláusula escalonada é útil e recomendada em contratos internacionais complexos e de longa duração em especial, pois permite às partes a possibilidade de resolver litígios mediante acordo durante o (muitas vezes longo) processo de execução e vigência do contrato; há de estipular o procedimento (prazos, modo de realização da mediação) porque uma das partes pode alegar vícios em sua implementação ou realização.

O escopo da mediação é, procedimentalmente, intervir para facilitar, ou restabelecer a capacidade de diálogo sobre situações conflituosas entre pessoas, grupos ou organizações. Também pode ser

\footnotetext{
12 Arts. 565 e 695 do Código de Processo Civil.

13 Pode-se consultar o regulamento da American Arbitration Association (EUA) em https:// www.mediation.org/mediation/faces/mediator_resources/standards_rules_procedures?_ afrLoop $=418453775973812$ \&_afrWindowMode=0\&_afrWindowld $=8705 j j 6 \mathrm{~h} \_1 \# \% 40 \% 3 \mathrm{~F}$ afrWindowld\%3D87o5jj6h_1\%26_afrLoop\%3D $418453775973812 \% 26$ _ afrWindowMode\%3D0\%26_adf.ctrl-state\%3D87o5jj6h_37; bem como da Câmara Internacional de Comércio (Paris) http://www.iccwbo.org/products-and-services/arbitration-and-adr/mediation/ rules/; e Deutsch Institution für Schiedsgerichtsbarkeit - Instituto Alemão de Arbitragem (Alemanha), http://www.dis-arb.de/en/16/rules/dis-mediation-rulesid31. E, ainda, sobre programas de mediação e conciliação de conflitos coletivos, ver SOUZA, L. M. de. Mediação de conflitos coletivos: a aplicação dos meios consensuais à solução de controvérsias que envolvem políticas públicas de concretização de direitos fundamentais. Belo Horizonte: Fórum, 2012, p. 173-201.
} 
compreendida e aplicada como um saber disciplinar, multidisciplinar, interdisciplinar e transdisciplinar, tais como saúde coletiva, psicologia, filosofia, antropologia, sociologia e direito ${ }^{14}$.

A definição legal do art. $1^{\circ}$, parágrafo único, da Lei 13.140/2015 é a seguinte:

Atividade técnica exercida por terceiro imparcial sem poder decisório, que, escolhido ou aceito pelas partes, as auxilia e estimula a identificar ou desenvolver soluções consensuais para a controvérsia.

Pode-se acrescentar que há formação de um processo de comunicação quando se enfatiza a responsabilidade e autonomia dos participantes e mediados que confere autoridade ao mediador, que pode aplicar técnicas como a identificação de questões, interesses e sentimentos, validação de sentimentos, despolarização do conflito, silêncio, inversão de papéis e escuta ativa ${ }^{15}$.

No que tange a espécies de mediações, alerta-se que aqui se defende que a mediação judicial de conflitos, em harmonia com o sistema jurídico pátrio, pode ser dividida em duas grandes espécies: a pública e a privada.

Entretanto, somente a espécie pública deve ser judicial, enquanto a privada pode ser judicial ou extrajudicial, e ambas podem ser cível/ não penal e penal. Porém, é envolvida num contexto público o âmbito penal ${ }^{16}$, ambiental, trabalhista, saúde, dentre outros, e, certamente, empresarial, escolar, societário, bancário, familiar se inserem no âmbito

14 O art. 694 do CPC/2015 esclareceu acerca do dever disposição do auxílio de profissionais de outras áreas de conhecimento para a mediação e conciliação, quando todos os esforços serão empreendidos para a solução consensual da controvérsia em ações de família.

15 Sobre técnicas de mediação ver SPENGLER, F. M. Retalhos de mediação [recurso eletrônico]. Santa Cruz do Sul: Essere nel Mondo, 2014, p. 44 a 71.

16 Cresce no Brasil o novo modelo, não exclusivamente punitivo, que foi definido pela Declaração da Costa Rica de Justiça Restaurativa que é processo capaz de colocar vítima e ofensor frente a frente com a finalidade de fomentar o arrependimento, a restituição, a reabilitação e a integração social. 
privado. Vale ressaltar que a lei ${ }^{17}$, com objetivo de evitar práticas protelatórias, dispõe que a mediação suspenda o prazo prescricional, ou seja, protege o exercício pleno do direito pela via judicial própria.

No que se refere à responsabilidade pelo pagamento das despesas da mediação judicial, é um dever das partes. E será do Estado no caso de concessão de justiça gratuita e nos casos pré-processuais, o novo Código de Processo Civil ${ }^{18}$. Todavia, o magistrado pode arbitrar os honorários do mediador e conciliadores. Por enquanto, o trabalho profissional do mediador é realizado com excelência e sem nenhum tipo de remuneração ou indenização, por motivos que aqui não é objetivo expor.

\subsection{PAPÉIS DE JUÍZES, MEDIADORES E ADVOGADOS}

Obstáculos e perigos exigem ultrapassagens, em especial na implementação da política nacional de estímulo à solução consensual dos conflitos de maneira efetiva e ampla. Nesse contexto, geram transtornos os excessos de controle por parte do Judiciário quando se beneficia de uma estrutura arcaica e seletiva. Há quem afirme que juízes temem pela redução de poder, advogados receiam redução de mercado de trabalho e os mediados (partes ou não de um processo judicial) não querem correr riscos num campo desconhecido, tampouco desejam aumento de custos.

No tange aos receios dos juízes, pode-se inferir algumas questões relacionadas às diferenças no exercício de suas atividades como as que decorrem das formações. O mediador, com avanço ou não da

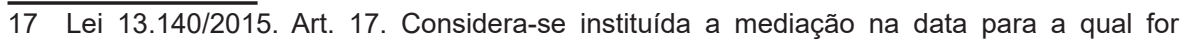
marcada a primeira reunião de mediação. Parágrafo único. Enquanto transcorrer o procedimento de mediação, ficará suspenso o prazo prescricional.

18 Art. 169 do CPC/2015. "As partes podem escolher, de comum acordo, o conciliador, o mediador ou a câmara privada de conciliação e de mediação. $\S 1^{\circ} \mathrm{O}$ conciliador ou mediador escolhido pelas partes poderá ou não estar cadastrado junto ao tribunal. § $2^{\circ}$ Inexistindo acordo na escolha do mediador ou conciliador, haverá distribuição entre aqueles cadastrados no registro do tribunal, observada a respectiva formação. $\S 3^{\circ}$ Sempre que recomendável, haverá a designação de mais de um mediador ou conciliador." 
sessão ou audiência, objetiva ter um papel biodegradáve ${ }^{19}$; enquanto, o juiz, em sentido oposto, tem papel não só de autopreservação como decisivo no conflito. Aqui são indispensáveis as preciosas elucidações do Juan Carlos Vezulla:

Temos que diferenciar a atuação dos profissionais liberais (entre os quais se encontram os conciliadores e em certa medida os mediadores acordistas), dos mediadores responsáveis, pois os outros profissionais têm o conhecimento e o aplicam sobre o paciente ou cliente de quem recebem as informações para que o profissional elabore um diagnóstico e o tratamento correspondente, a solução. Essa situação gera a dependência regulatória. Não posso sem um médico, não posso sem um advogado, não posso sem. Enquanto que o mediador responsável parte de seu não saber e recebe as informações para que os mediados se autodiagnostiquem e assim possam solucionar seus problemas por conta própria. O mediador não dá nenhuma orientação e nem solução do problema, pois parte da humildade de reconhecer que são os mediados os que sabem das suas vidas. ${ }^{20}$

Portanto, as atividades do juiz e do mediador não só são diferentes como opostas. O juiz, conforme o processo avança, tornase indispensável, ao contrário do mediador, que sucesso equivale ao afastamento diante do exercício pleno da autonomia dos mediados em razão de ter poder de decisão limitado ou não autoritário.

19 VEZZULLA, J.C. Mediação de conflitos: a questão coletiva, p. 45 in Comissão Técnica de Conceitos do Programa Mediação de Conflitos - CTC - PMC. Programa mediação de conflitos: uma experiência de mediação comunitária no contexto das políticas públicas. Belo Horizonte: Arraes Editores, 2011.

20 Ibidem, p. 45-46. 
No entanto, por essa e outras razões, Vezzulla ${ }^{21}$ adverte que a formação do mediador, no Brasil, deve ser cautelosa e deve ter ampliado o número horas de estágio, pois a atividade do mediador requer, além do conhecimento teórico, o desenvolvimento de habilidades que exigem tempo de amadurecimento.

A importância do papel do advogado é muito bem-vinda, mesmo que os mediados tenham o poder de decidir autonomamente, deve informar, aconselhar e assessorar o cliente sobre a escolha da forma de resolução conflito aplicável ao caso concreto. Porém, é necessário que o advogado tenha uma postura não combativa ou adversarial e sim colaborativa, e neste contexto ter a certeza da importância da colaboração.

O advogado tem a missão perante o seu cliente de explicar os objetivos da mediação, auxiliar na inserção de cláusulas de mediação em contratos, ajudar na escolha do mediador ou da câmara de mediação para gestão do procedimento, bem como auxiliar na formulação de propostas mais satisfatórias e juridicamente possíveis.

Ainda sobre advogados, impossível não mencionar que o art. 168 e $\S 5^{\circ}$ do CPC dispõe que os tribunais manterão cadastro de conciliadores e mediadores, bem como os conciliadores e mediadores cadastrados. Mas se advogados estarão impedidos de exercer a advocacia nos juízos em que exerçam a mediação, tais exigências precisam, no mínimo, serem reguladas pelo Conselho Nacional de Justiça, porque há problemas e aqui são necessários dois destaques: é um grande desincentivo para profissionais atuarem no âmbito judicial; e não são compatíveis com os impedimentos previstos no Código de Processo Civil e o Estatuto da advocacia22.

Enfim, é inegável a necessidade de se capacitar os juízes, defensores, promotores, e advogados para que possam auxiliar na disseminação da cultura de paz e de cidadãos autônomos, ou

21 I Congresso Internacional de Mediação. Porto Alegre $1^{\circ}$ e 2/12/2016.

22 Mais sobre essa temática encontra-se em pode ser HALLAK, E. Impedimentos, impossibilidades e penalidades referentes ao mediador, p. 169-178. ALMEIDA, D.A.R.; PANTOJA, F.M.; PELAJO, S. A mediação no novo código de processo civil. Rio de Janeiro: Forense, 2015. 
individualizados, para dirimir seus próprios conflitos. Nunca é demais ressaltar que os efeitos do regime democrático são mais bem sentidos e aproveitados quando se valoriza e se fortalece o cidadão emancipado ou individualizado.

\subsection{FORMAS DE MEDIAÇÃO E OUTROS MÉTODOS DE SOLUÇÃO DE CONFLITOS CONSENSUAIS}

Em geral, o formato mais eficaz e comum de uma sessão, ou audiência ${ }^{23}$, de mediação é a comediação, realização em dupla de mediadores que potencializa o diálogo entre saberes presentes na formação dos mediadores, além de haver um observador do trabalho dos mediadores.

A história recente das diferentes formas de trabalhar com a mediação informa que a mediação se estruturou a partir da negociação da escola de direito de Harvard como uma alternativa ao Poder Judiciário que se desenvolveu e se consolidou integrando distintas áreas do conhecimento.

No entanto, são consideradas como clássicas ${ }^{24}$, além do Modelo Tradicional-Linear de Harvard, também conhecida como "mediação satisfativa", o Modelo Transformativo de Bush e Folger e o Modelo Circular-Narrativo de Sara Cobb ${ }^{25}$. Alguns doutrinadores incluem o modelo de Luis Alberto Warat ou Waratiano, mas que não será

\footnotetext{
23 A doutrina apresenta diferenças entre pré-mediação (que pode ser tanto numa sessão quanto numa audiência), sessão de mediação (sigilo parcial ou total) e audiência de mediação (publicidade), neste sentido ver GALVÃO FILHO, M.V. Audiência(s) e sessão(ões) de Mediação na lei de Mediação (Lei 13.140/2015). In: ZANETI JR., H.; CABRAL, T.N.X. Justiça multiportas: mediação, conciliação, arbitragem e outros meios de solução de conflitos. Salvador: Juspodivm, 2016, p. 509 a 528.

24 ALMEIDA, T.; PELAJO, S.; JONATHAN, E. Mediação de conflitos. Salvador: Juspodivm, 2016, p. 189-240; MENDONÇA, R. A ética da mediação ambiental. Rio de Janeiro: Lúmen Juris, 2014, p. 56-46. Nesta obra e páginas citadas levantam-se questões interessantes, destacandose a classificação de Ellen Waldman baseada na postura do mediador frente às normas sociais e sua relevância para resultado da mediação.

$25 \mathrm{O}$ art. 166 prevê no $\S 3^{\circ}$ a admissão de técnicas negociais, com o objetivo de proporcionar ambiente favorável à autocomposição.
} 
examinado aqui. Desde já, registra-se que nenhum dos modelos é melhor que o outro. São abordagens diferentes e aplicáveis aos diferentes tipos de conflitos.

Na mediação satisfativa a comunicação é linear, ou seja, o mediador tem como função ser um facilitador da comunicação para poder conseguir um diálogo efetivo. Esse modelo propõe que as partes devem se expressar em uma espécie de catarse, sendo que o método utiliza a separação das pessoas do problema, foco nos interesses e não nas posições, as opções devem ser de benefício, satisfações mútuas, e critérios e fundamentos objetivos sem pressão arbitrária. As críticas são no sentido de que não há objetivo de trabalhar os sentimentos e o contexto em que produzido o conflito; e que há mais foco no acordo mútuo.

O modelo transformativo é considerado um modelo completo, tem a meta de dar novas formas de relacionamentos entre as pessoas no sentido de mudar relacionamento que lhe cause mal-estar, sendo que o conflito é entendido como motor de transformação trabalhando-se para o protagonismo das partes e coprotagonismo, o mediador atua com reuniões conjuntas e individuais. A meta é a modificação da relação entre as partes, portanto, o oposto do modelo de harvardiano, pois não objetiva apenas obter o acordo e sim a transformação das relações.

Enquanto o modelo circular, ou narrativo vislumbra a desestabilização das pessoas, com a desconstrução das histórias iniciais ou dominantes e criação de histórias alternativas, há a preocupação com a circularidade e a interdependência das pessoas, buscando analisar um conjunto de causas remotas que podem ter alimentado o conflito.

Mas será que as formas de mediação são o caminho natural para conflitos pré-processuais, ou processuais? A resposta é negativa. Não é tão simples quanto parece encaminhar um conflito para uma alternativa, ou opção adequada (se fortalece a tendência de utilizar resolução adequada de disputas - RAD) para solucionar o problema conflitual.

Portanto, o escopo é encaminhar o conflito para a "porta" que for mais apropriada, não há hierarquia, e se não se adequar a nenhuma, adjudica-se ou encaminha-se ao Poder Judiciário. E mais, não há necessidade de se oferecer todos os mecanismos para ser reconhecido 
com multiportas, tanto que no Brasil, até o momento, os fóruns disponibilizam apenas a mediação e a conciliação, que são adequados à formação da cultura de pacificação de conflitos.

Os procedimentos primários de resolução de conflitos são a negociação ${ }^{26}$, mediação ${ }^{27}$, conciliação e arbitragem. A doutrina também apresenta cinco modalidades denominadas "híbridas", combinação dos tipos primários, que são: o julgamento privado, a análise neutra dos fatos através de um perito, o minitrial, o ombudsman e o summary jury trial. E, ainda, o procedimento intitulado med-arb ou arb-med, resultado da combinação da mediação e da arbitragem ${ }^{28}$.

Não é objetivo aqui examinar todas as espécies primárias e híbridas, apenas destacar alguns aspectos de três procedimentos. No minitrial um terceiro eleito é um conselheiro no procedimento, que, na obtenção de um acordo, gerará um contrato decorrente do júri simulado, isto é, do espaço para a exposição dos interesses e argumentos que integram o caso entre os participantes. O ombudsman, ou ouvidor, comum na Escandinávia, é aplicado em conflitos de direito público no qual a instituição estatal exerce, informalmente, um papel investigativo. O med-arb ou arb-med é um sistema escalonado no

26 Sobre a mediação sem mediador ou negociação direta ou resolução colaborativa ver CABRAL, A. do P.; CUNHA, L. C. Negociação direta ou resolução colaborativa de disputas (collaborative law): "Mediação sem mediador". In: ZANETI JR., H.; CABRAL, T. N. X. Justiça multiportas: mediação, conciliação, arbitragem e outros meios de solução de conflitos. Salvador: Juspodivm, 2016, p. 709 a 726.

27 Neste trabalho o foco não é a mediação extrajudicial, que é uma forma extraordinariamente criativa em relação à experiência mundial, tampouco é sobre a mediação privada que é um mercado em formação no país. A Lei 13.140/2015 regula com profundidade aspectos da mediação judicial, extrajudicial e envolvimento de entes públicos. O que salta aos olhos é que a mediação privada é eletista e a mediação decorrente da demanda pública é voltada para muitos ou maior número de pessoas. Neste sentido ver ASSMAR, G.; PINHO, D. Mediação privada um mercado em formação no Brasil. In: ZANETI JR., H.; CABRAL, T. N. X. Justiça multiportas: mediação, conciliação, arbitragem e outros meios de solução de conflitos. Salvador: Juspodivm, 2016, p. 589 a 606.

28 WRASSE, H.P.; DORNELLES, G.D. Fórum múltiplas portas e os possíveis caminhos para solucionar os conflitos, p. 27-45. In: SPENGLER, F.M.; SPENGLER NETO, T. (orgs.). Do conflito à solução adequada: mediação, conciliação, negociação, jurisdição e arbitragem [recurso eletrônico]. Santa Cruz do Sul: Essere nel Mondo, 2015. 
qual as partes concordam em realizar a mediação ou arbitragem, e no caso de o método escolhido não resultar uma solução, passa-se à aplicação do outro procedimento ao conflito em questão, e apresenta-se separadamente as funções do mediador e do árbitro; isso proporciona maior segurança, considerando que se não for frutífero a med-arb na elaboração de um acordo, passa-se a arb-med.

Enfim, retomando a ideia de classificação em conjunto com a particularidade das múltiplas portas, denota-se que há uma busca das possíveis naturezas do conflito e o respectivo enquadramento. Há uma racionalização da forma de solução que pode seguir com base na classificação de mediação, que também visa a ampliar as vantagens e chances de êxito com a redução de desvantagens. Mas depende do tribunal o tipo a ser estabelecido e qual o encaminhamento poderá ser feito como, por exemplo, a partir da análise dos tipos de controvérsias ou levando em consideração o valor atribuído à causa.

\section{PRINCÍPIOS APLICÁVEIS NA MEDIAÇÃO JUDICIAL}

\subsection{OBSERVAÇÕES PONTUAIS SOBRE PRINCÍPIOS E DIREITOS FUNDAMENTAIS}

$\mathrm{Na}$ sociedade contemporânea, conforme discorre Baltazar Júnior $^{29}$, as fontes de agressão aos direitos fundamentais não provêm somente do Estado. Respostas inadequadas a agressões também são originadas nos centros de poder não estatais, e por esta razão os direitos fundamentais passam a desempenhar também a função de defesa contra ameaça e agressões. Restrições a direitos fundamentais exigem que, quanto maior for a afetação, maior será o peso das razões

29 BALTAZAR JUNIOR, J. P. A doutrina da proibição de insuficiência ("Untermassverbot"). In: HECK, L. A. (org.). Direitos fundamentais, teoria dos princípios e argumentação. Porto Alegre: SAFE, 2014, p. 74. Nas p. 81-88 o jurista brasileiro apresenta as críticas da proibição de insuficiência, destacando a autonomia da proibição de insuficiência frente à proibição de excesso e a compatibilidade entre proibição de insuficiência e proibição de excesso. 
que a fundamentam (Lei do Sopesamento) $)^{30}$.

Nesse sentido, conforme o tratamento dispensado no novo Código Civil, a mediação judicial fortalece a indisponibilidade da tutela constitucional adequada aos direitos fundamentais e a preservação do espírito constitucional democrático, em especial ao devido processo legal e do amplo acesso à justiça. Portanto, transitou-se da tutela processual, que é um fim em si mesma, para tutela de direitos que é, efetivamente, a finalidade do processo ${ }^{31}$.

Antes de ingressar nos princípios nucleares deste trabalho, retoma-se a ideia de que nas realizações dos direitos fundamentais houve a necessidade de institucionalização em direitos positivos. E na interpretação e aplicação dos direitos fundamentais está a distinção entre regras e princípios.

Argumentos sob a perspectiva do participante não anula a necessidade de demonstrar a destruição da hierarquia de primazias prima facie, nos princípios e nas regras, nas possíveis associações de normas de direito fundamental. Os princípios para valer definitivamente dependem do exame de possibilidades fáticas e jurídicas que contribuem para a inserção da ponderação com princípios contrários; as regras têm caráter prima facie forte porque têm determinações jurídicas e fáticas ${ }^{32}$.

30 ALEXY, R. Teoria dos direitos fundamentais. Tradução Virgílio Afonso da Silva. São Paulo: Malheiros, 2008, p. 352 e 611, quando ressalta que os direitos fundamentais não podem ser divididos de uma forma tão refinada que excluam impasses estruturais que poderiam torná-los sem importância ou impasses reais no sopesamento, de forma a torná-los praticamente sem importância. Importa registrar que um grande objetivo da teoria alexyana foi a construção de um conceito do direito, que inseriu correção com conceitos morais. Ver a tradução do conceito de direito de Alexy em LUDWIG, 2014, p. 321. Há outra tradução do conceito em ALEXY, R. Conceito e validade do direito. Trad. Gercélia Batista de Oliveira Mendes. São Paulo: Martins Fontes, 2011a, p. 151.

31 DIDIER JR., F.; ZANETTI JR., H. Justiça multiportas e tutela constitucional adequada: autocomposição em direitos coletivos. In: ZANETTI JR., H.; CABRAL, T. N. X. Justiça multiportas: mediação, conciliação, arbitragem e outros meios de solução adequada para conflitos. Salvador, Juspodivm, 2016, p. 36.

32 A argumentação dos princípios é a parte importante da argumentação sistemática, todos os princípios de direito e todas as normas jurídicas têm caráter deontológico (de dever). De modo amplo, tem-se que cuidar com sedutores parâmetros como da primazia do bem coletivo 
Ludwig $^{33}$ ressalta que o princípio da proporcionalidade como guia da ponderação não representa garantia contra um abuso retórico quando não poderia ser mais um sinônimo de racionalidade e bom senso, que poderia ser tomado como um conceito vago e apenas dourar um argumento fraco. Assim, observa que, por detrás da estrutura argumentativa da proporcionalidade, operam-se diferentes modelos de argumentação que são proporcionalidade como proibição de excesso na intervenção em direitos fundamentais; proporcionalidade como proibição de insuficiência em deveres de proteção de direitos fundamentais, e proporcionalidade como barreira nos princípios da igualdade.

Portanto, em consonância com um arcabouço teórico, os princípios não são tomados com vaguezas conceituais. Nesse sentido, percebese a necessidade de se apurar se princípios atribuídos à mediação judicial são, tecnicamente, normativos, e se não são, efetivamente, uma regra. A doutrina ${ }^{34}$ alerta que ora o legislador parece fazer referência a princípios basilares, ora parece se referir a normas com estrutura de regras. Exemplificando, o princípio da oralidade, intimamente ligado ao da informalidade, tem o caráter comunicativo ou regulativo sobre as sessões e audiências, sobre o qual não se deve ter o registro de todas as informações.

\subsection{A DIVERSIDADE DE FONTES DOS PRINCÍPIOS DA MEDIAÇÃO: A INDISSOCIABILIDADE PRÁTICA DA VOLUNTARIEDADE E BOA- FÉ; E DA CONFIDENCIALIDADE E INFORMALIDADE}

A mediação é uma possibilidade real de win-win situation, ou

sobre direitos individuais, pois essa situação pode desembocar no holismo jurídico, "segundo qual todas premissas já estão contidas ou escondidas no sistema jurídico e, ainda, somente precisam ser descobertas" em Constitucionalismo discursivo. 3. ed. Porto Alegre: Livraria do Advogado, 2007, p. 39.

33 LUDWIG, op. cit., p. 448.

34 PEIXOTO, R. Os "princípios" da mediação e da conciliação: uma análise da Res. 125/2010 do CNJ, do CPC/2015 e da Lei 13.140/2015. In: ZANETI JR., H.; CABRAL, T. N. X. Justiça multiportas: mediação, conciliação, arbitragem e outros meios de solução de conflitos. Salvador: Juspodivm, 2016, p. 91 a 108. 
situação em que todos os envolvidos podem ter satisfação com o desfecho. Nesse contexto, muitos princípios, de fontes variadas, contribuem para a realização dessa situação. E caso a audiência ou sessão de mediação não for realizada em conformidade com os princípios aplicáveis ao caso concreto, todo o procedimento poderá ser passível de anulação.

Neste tópico serão nominados princípios constantes no Fórum Nacional de Mediação e Conciliação (FONAMEC) ${ }^{35}$, Código de Ética dos Mediadores e Conciliadores (Resolução 125/2010 do CNJ, anexo III, arts. $1^{\circ}$ a $\left.8^{\circ}\right)^{36}$, a Lei $13.140 / 2015$, o Código de Processo Civil, no art. 166 e a Constituição Federal ${ }^{37}$.

No que se refere ao Código de Ética dos Mediadores e Conciliadores, destacam-se apenas três dos que são, rotineiramente, mais aplicados em sessões, ou audiência de mediação. Primeiro, o dever de diligência que assegura a qualidade, a credibilidade do processo e a excelência dos serviços prestados. Transparência, o segundo destaque, é um dever que, na prática mediativa, ajuda no estabelecimento da relação de confiança (rapport) e a tranquilizar os mediados sanando dúvidas sobre o método; por consequência, a mediação deve ser conduzida com idoneidade e transparência com informações sobre o processo, seus alcances e limites, de maneira clara e objetiva. Terceiro, é o dever do respeito que não envolve apenas a ordem pública e leis vigentes, mas a solidariedade e a cooperação, levando-se em consideração que são os mediados os protagonistas.

O Fórum Nacional de Mediação e Conciliação (FONAMEC) lança um olhar institucional que são as boas práticas de mediação por tribunais brasileiros, que até mesmo antes da Resolução 125/2010 já avançavam no sentido de serem verdadeiros modelos de efetividade da

35 A especificidade do último. 2016. Disponível em: <fonamec.tjmt.jus.br/Fichalnscricao/ Fonamec4 /\#realizarinscricoes> Acesso em: 7 fev. 2017.

36 Disponível em: <http://www.cnj.jus.br/busca-atos-adm?documento=2579> Acesso em: 7 fev. 2017.

37 MORI, A. H. Princípios gerais aplicáveis aos processos de mediação e de conciliação. In: GUNTHER, L. E.; PIMPÃO, R. D. Conciliação: um caminho para a paz social. Curitiba: Juruá, 2013, p. 176 a 195, apresenta os princípios aplicáveis à mediação e conciliação, os relacionados com os participantes, os relacionados com o procedimento e com os mediadores. 
mediação judicial, e destacam-se três. Uma, o cuidado de evitar acordo prematuro, que não haja um "casamento com a hipótese"; duas, evitar pautar o sucesso da mediação em dados baseados exclusivamente no número de acordos obtidos; três, fazer uma pesquisa de satisfação e a divulgação criteriosa de dados estatísticos para fins acadêmicos, mediante a autorização e preservação dos envolvidos.

Na Lei 13.140/2015, conhecida como Lei da Mediação, há cinco princípios que se encontram também no Código do Processo Civil e há apenas três acréscimos que são: a isonomia das partes (no qual se busca que a parte se perceba ouvida), a busca de consenso e a boa-fé.

No entanto, no mandamento processual civil, o art. 166 dispõe sobre os princípios da independência, da imparcialidade, da autonomia da vontade ou a livre autonomia dos interessados no que diz respeito à definição das regras procedimentais, inclusive da confidencialidade, da oralidade, da informalidade e da decisão informada.

Cumpre salientar que a mediação, bem como os demais métodos autônomos de resolução de conflitos, é abrangida pela segurança jurídica e, à medida que os vícios que os atingirem, como fraude, dolo ou erro, podem ser judicialmente discutidos e são passíveis de rescisão ou anulação da decisão nos casos previstos. Se houver, por exemplo, a violação da confidencialidade, as informações utilizadas tornam-se prova ilícita, conforme art. $30, \S 2^{\circ}$, da Lei de Mediação, e pode caber indenização, no caso de dano.

O cotidiano nas sessões e audiência de mediação tem apontado espécies de princípios indissociáveis com regularidade, e aqui destacamos dois em pares. A voluntariedade, em muitas situações, traz a boa-fé necessária para se restabelecer diálogo e na propositura de soluções pelos próprios mediados. Enquanto a confidencialidade se mostra necessária com a informalidade quando lançada, por exemplo, para proteger a confidencialidade nas minutas da mediação, que geralmente constam os termos com ou sem entendimento.

É essencial que os participantes possuam boa-fé objetiva ou processual e, consequentemente, a intenção verdadeira de abertura ao momento ou ao tempo. No entanto, a boa-fé é mais bem compreendida como um dos tipos do princípio da eticidade ou da conduta ética, pois 
é um complemento ao que é declarado e convencionado e, o mais importante, está inserida em um valor maior que a dignidade humana ou a pessoa humana como fonte de valores.

A voluntariedade confere às partes o direito de participar do procedimento de forma livre, exercendo em plenitude a autonomia individual $^{38}$ sem interferência, ou coações. E a boa-fé complementa com uma autolegislação em consonância com a clássica concepção kantiana de autonomia da vontade individual, que é a imposição da lei a si mesmo de maneira com finitude; a autodeterminação é um dos principais alicerces da revolução na modernidade ${ }^{39}$.

No que tange à informalidade, esta é caracterizada pela ausência de uma estrutura previamente estabelecida e pela inexistência de norma material quanto ao procedimento, mas, como visto, podem ser aplicadas técnicas de negociação. Ainda sob os auspícios desse princípio, esta oralidade é caracterizada pela simplicidade e clareza que fortalece outros princípios. A informalidade, aliada à oralidade, na vida cotidiana da mediação, mostra-se como barreira que evita a formação de espirais de conflitos.

A confidencialidade é um estímulo aos métodos de autocomposição e abrange todas as informações obtidas na mediação, salvo autorização expressa das partes, violação à ordem pública ou às leis vigentes. E o dever de sigilo, intrínseco nesse princípio, também se refere às funções de mediador e membros da equipe (observadores, supervisores nos CEJUSC, etc.).

$\overline{38}$ Assegurada na Constituição Federal art. $5^{\circ}$, caput e especificamente nos incisos II, IV, X e LIV. 39

Ver LUDWIG, R. J. A norma de direito fundamental associada: direito, moral e razão em Robert Alexy. Porto Alegre: SAFE, 2014, p. 168-179. Essa obra, em várias passagens, retoma pensamento kantiano, especialmente como um expoente da consciência da finitude humana e um divisor de água para a compreensão da razão humana prática. Demonstrou, em várias passagens, que tentar colocar no lugar da lei moral máximas particulares e não universalizáveis é espontaneísmo moral ou heteronomia que se afina com a postura solopsista. 


\subsection{A INTERLIGAÇÃO DA MEDIAÇÃO COM DEMOCRACIA E DIREITOS FUNDAMENTAIS SOB A PERSPECTIVA DOS PRINCÍPIOS CONSTITUCIONAIS DO ACESSO À JUSTIÇAE DA SOLIDARIEDADE}

A relação dos direitos fundamentais e democracia é próxima e profunda. Mas não simples, pois se caracteriza pela conflitividade e contraditoriedade. Daí a necessidade de um tribunal constitucional argumentativo, que é o espaço para a representação ${ }^{40}$ argumentativa, pois atua para além da representação tradicional do cidadão, no qual a unidade do Estado não visa somente a uma concepção material ou funcional.

A natureza da democracia é levar o cidadão a sério, e neste sentido a afirmação de Robert Alexy é contundente: "Democracia é, sob esse aspecto, reflexiva" 41 .

Portanto, nesse sentido, os meios alternativos de composição de conflitos fundamentam-se na democracia e nos direitos fundamentais. Pois, ao mesmo tempo, são formas de garantias e de controle a participação dos próprios cidadãos-mediados na administração da justiça.

Nesse contexto, é fácil inferir que a solidariedade está enlaçada pelo princípio nuclear dos direitos fundamentais e da República do país, que é o da dignidade humana. E mais, o efetivo acesso à justiça

\footnotetext{
40 A necessidade da representação foi desenvolvida pelos maiores pensadores, conforme ressaltam doutrinadores. Em Montesquieu, "A grande vantagem dos representantes é que eles são capazes de discutir os assuntos. O povo não é nem um pouco capaz disso, o que constitui um dos grandes inconvenientes da democracia" (Cfr. MONTESQUIEU. O espírito das leis. 3. ed. São Paulo: Martins Fontes, 2005, p. 171. Aristóteles, já antevira o perigo, inerente às democracias, de que a força do número da maioria imperaria sobre as pessoas de bem; por essa razão recomendou que não se entreguem os cargos mais importantes à maioria dos cidadãos livres por causa da sua corrupção e ignorância, mas que, ao invés disso, pudessem participar através da eleição e censura (Cfr. ARISTÓTELES. A política. 3. ed. São Paulo: Martins Fontes, 2006, p. 173. Em KANT, I. Sobre la paz perpétua. Madrid: Aliança, 2012, p. 56, sentenciou: "Toda forma de governo que no sea representativa es em propriedade uma no forma [...]", em português À paz perpétua e outros opúsculos. Lisboa: Edições 70, 2008, p. 141).

41 ALEXY, R. Minha filosofia do direito a institucionalização da razão. Constitucionalismo discursivo. Porto Alegre: Livraria do Advogado, 2011b, p. 28.
} 
e à solidariedade são instrumentos catalizadores da mediação judicial sob contexto do Estado Constitucional Democrático de Direito, para que se forme e estabeleça uma sociedade mais unida, participativa e mantenedora da paz social.

A pacificação de conflitos e o acesso à justiça ${ }^{42}$ são indissociáveis e devem ser universalmente garantidos de forma efetiva e não meramente formais. Para esse fim, tem-se que contornar ou ultrapassar empecilhos como a morosidade, a ausência de políticas públicas voltadas à divulgação dos possíveis caminhos para reconhecimentos sobre seus próprios direitos e os meios adequados e o excesso de formalidade para a resolução de questões pouco complexas que refletem o distanciamento da realidade da população.

O cidadão torna-se protagonista judicial ou "operador processual ativo" quando acessa à justiça efetivamente, em especial, nos meios alternativos de solução de conflitos. É uma maneira de descentralização da jurisdição processual ${ }^{43}$, que é quase exclusiva dos juízes togados, retornando o processo para a participação democrática.

As bases do acesso à justiça encontram-se ameaçadas quando a mediação, e outros meios de pacificação de conflitos, servem de abrigo para livrar dos riscos de um processo judicial, que muitas vezes é lento, ineficaz e oneroso, e até mesmo para evitar práticas protelatórias a lei da mediação ${ }^{44}$.

Quando conseguimos superar obstáculos que envolvem o acesso à justiça e opta-se por um dos meios de pacificação de conflitos ingressase na direção da consolidação da solidariedade $\left(\mathrm{CF} \text {, art. } 3^{\circ}, \mathrm{I}\right)^{45}$, pois o objetivo do agir com outro faz com que todos sejam corresponsáveis num movimento de unificação da humanidade para mundo civilizado

42 Art. $5^{\circ}, \mathrm{XXXV}, \mathrm{C} F / 88$ : "a lei não excluirá da apreciação do Poder Judiciário lesão ou ameaça a direito".

43 Ver GUTIERREZ, D. M.; CUNHA, J.P. Jurisdição processual e democracia: advento da audiência de conciliação e mediação, efetivação dos meios equivalentes e acesso à justiça. Revista Opinião Jurídica - Revista do curso de Direito da Unichristus, Fortaleza, n. 17, p. 108131, 2015.

44 Art. 17, parágrafo único.

45 Vários dispositivos constitucionais estão relacionados com o princípio da solidariedade, tais como os artigos 40, 194, 195, 196, 203, 205, 227 e 230. 
e não bárbaro. O reconhecimento dá direito à solidariedade, além dos direitos individuais e sociais com a expansão para o direito à paz, representando uma época de fortalecimento democrático.

O acesso à justiça e à solidariedade são fundamentos da República Federativa do Brasil. Portanto, há de se fazer valer concretamente no âmbito das ações do Estado, que deve estimular os meios de pacificação dos vínculos entre os seres humanos, fortalecendo a significância do outro que refletirá no sentido que se busca da própria sociedade.

Enfim, o acesso à justiça e à solidariedade são alicerces basilares da democracia e dos direitos fundamentais. A mediação atinge a plenitude quando se considera o outro ultrapassando as superficialidades, quando a efetividade é alcançada em resoluções alternativas de conflitos aproximando a sociedade aos ideais supremos da nação brasileira, justiça e solidariedade.

\section{CONCLUSÃO}

O presente artigo buscou esclarecer parâmetros conceituais, com ênfase nos procedimentos sob uma perspectiva constitucional da mediação judicial no país.

Para tanto, foi necessário fixar objetivos da mediação que facilita, ou restabelece a capacidade de diálogo sobre situações conflituosas entre pessoas, grupos ou organizações. Também esclareceu que a mediação, ao lado da arbitragem, conciliação e negociação, edifica formas acessórias ou híbridas de resolução de conflitos.

A vivência da mediação judicial comprova o que a doutrina assevera quanto a necessidade e importância de se capacitar juízes, defensores, promotores e advogados para que possam auxiliar na disseminação da cultura de paz. De igual forma, para que a sociedade aproveite a nacionalização do instrumento para se desenvolver uma cultura de paz e de justiça.

Estampou-se doutrina consagrada sobre princípios, democracia e direitos fundamentais. Foi apresentada a diversidade de fontes dos princípios da mediação e ressaltou-se a regular indissociabilidade da 
voluntariedade e boa-fé; e da confidencialidade e informalidade, sendo que esse se mostra interessante para que se evite formação de novos espirais de conflitos nas sessões ou audiências de mediação.

À guisa de conclusão, é igualmente fundamental deixar claro que para preservar e potencializar a mediação judicial, extrajudicial ou pré-processual é necessário compreendê-la mais que um auxiliar no problema estrutural do Poder Judiciário. Ela tem o papel de desenvolver o potencial de promover autorresponsabilidades aos envolvidos em conflitos para soluções dialogadas, justas e pacíficas.

Conclui-se por derradeiro que a mediação, para além de um método adequado de resolução de conflitos, fortalece o exercício da cidadania conduzindo a democracia para patamares discursivo e argumentativo sólidos.

\section{REFERÊNCIAS}

ALEXY, R. La teoría de la argumentación jurídica - la teoria del discurso racional como teoría de la fundamentacion jurídica. Madrid: Centro de Estudios Constitucionales, 1997.

. Constitucionalismo discursivo. 3. ed. Porto Alegre: Livraria do Advogado, 2007.

ASSMAR, G.; PINHO, D. Mediação privada - um mercado em formação no Brasil. In: ZANETI JR., H.; CABRAL, T. N. X. Justiça multiportas: mediação, conciliação, arbitragem e outros meios de solução de conflitos. Salvador: Juspodivm, 2016. p. 589-606.

BALTAZAR JUNIOR, J. P. A doutrina da proibição de insuficiência (“Untermassverbot”). In: HECK, L. A. (org.). Direitos fundamentais, teoria dos princípios e argumentação. Porto Alegre: SAFE, 2014.

BIANCHI, A. A.; JONATHAN, E.; MEURER, O. A. Teorias do conflito. In: ALMEIDA, T.; PELAJO, S.; JONATHAN, E. Mediação de conflitos. Salvador: Juspodivm, 2016. p. 71-83. 
BURKARD, F.-P.; PRECHET, P. (orgs.). Metzler Lexukon

Philosophie. 3. Auflage. Stuttgart: Verlag J. B. Metzler, 2008.

COMISSÃO TÉCNICA DE CONCEITOS DO PROGRAMA MEDIAÇÃO DE CONFLITOS - CTC - PMC. Programa mediação de conflitos: uma experiência de mediação comunitária no contexto das políticas públicas. Belo Horizonte: Arraes Editores, 2011.

CUNHA, L. C. Negociação direta ou resolução colaborativa de disputas (collaborative law): "Mediação sem mediador". In: ZANETI JR., H.; CABRAL, T. N. X. Justiça multiportas: mediação, conciliação, arbitragem e outros meios de solução de conflitos. Salvador: Juspodivm, 2016. p. 709-726.

ENTELMAN, R. F. Teoría de conflitos - Hacia un nuevo paradigma. Barcelona: Gedisa, 2009.

GALVÃO FILHO, M. V. Audiência(s) e sessão(ões) de mediação na lei de mediação (Lei n. 13.140/2015). In: ZANETI JR., H.; CABRAL, T. N. X. Justiça multiportas: mediação, conciliação, arbitragem e outros meios de solução de conflitos. Salvador: Juspodivm, 2016. p. 509-528.

GUTIERREZ, D. M.; CUNHA, J. P. Jurisdição processual e democracia: advento da audiência de conciliação e mediação, efetivação dos meios equivalentes e acesso à justiça. Revista Opinião Jurídica - Revista do curso de Direito da Unichristus, Fortaleza, n. 17, p. 108-131, 2015.

HALLAK, E. Impedimentos, impossibilidades e penalidades referentes ao mediador, p. 169-178. In: ALMEIDA, D.A.R.; PANTOJA, F.M.; PELAJO, S. A mediação no novo código de processo civil. Rio de Janeiro: Forense, 2015.

HOLLERBACH, A. Ciência do direito. Tradução Eduardo Schenato Piñeiro. In: HECK, L. A. (org.). Direito natural, direito positivo, direito discursivo. Porto Alegre: Livraria do Advogado, 2010. p. 13-24. 
LUDWIG, R. J. A norma de direito fundamental associada: direito, moral e razão em Robert Alexy. Porto Alegre: SAFE, 2014.

MENDONÇA, R. A ética da mediação ambiental. Rio de Janeiro: Lúmen Juris, 2014.

MORI, A. H. Princípios gerais aplicáveis aos processos de mediação e de conciliação. In: GUNTHER, L. E.; PIMPÃO, R. D. Conciliação: um caminho para a paz social. Curitiba: Juruá, 2013. p. 165-198.

SPENGLER, F. M. Retalhos de mediação [recurso eletrônico]. Santa Cruz do Sul: Essere nel Mondo, 2014.

SOUZA, L. M. de. Mediação de conflitos coletivos: a aplicação dos meios consensuais à solução de controvérsias que envolvem políticas públicas de concretização de direitos fundamentais. Belo Horizonte: Fórum, 2012.

TARTUCE, F. Mediação nos conflitos civis. 2. ed. Rio de Janeiro: Forense, 2015.

VEZZULLA, J. C. Mediação de conflitos: a questão coletiva. In: Comissão Técnica de Conceitos do Programa Mediação de Conflitos - CTC - PMC. Programa mediação de conflitos: uma experiência de mediação comunitária no contexto das políticas públicas. Belo Horizonte: Arraes Editores, 2011. p. 45.

$$
\begin{aligned}
& \text { Recebido em | 16/02/2017 } \\
& \text { Aprovado em | 21/08/2017 }
\end{aligned}
$$

Revisão Português/Inglês: Smirna Cavalheiro 


\section{SOBRE A AUTORA | ABOUT THE AUTHOR}

\section{TÂNIA MARIA DOS SANTOS}

Doutora em Direito pela Universidade Federal do Rio Grande do Sul (UFRGS). Mestra em Direito pela Universidade Luterana do Brasil (ULBRA). Bacharela em Direito pelo Centro Universitário de Brasília (UniCEUB). Advogada. E-mail: tanniasantos@hotmail.com. 